\title{
Coupling GIS and LCA for biodiversity assessments of land use
}

\author{
Part 2: Impact assessment
}

\author{
Roland Geyer • Jan P. Lindner • David M. Stoms • \\ Frank W. Davis • Bastian Wittstock
}

Received: 11 August 2009/Accepted: 31 May 2010 / Published online: 15 June 2010

(C) The Author(s) 2010. This article is published with open access at Springerlink.com

\begin{abstract}
Purpose Geospatial details about land use are necessary to assess its potential impacts on biodiversity. Geographic information systems (GIS) are adept at modeling land use in a spatially explicit manner, while life cycle assessment (LCA) does not conventionally utilize geospatial information. This study presents a proof-of-concept approach for coupling GIS and LCA for biodiversity assessments of land use and applies it to a case study of ethanol production from agricultural crops in California.

Materials and methods In Part 2 of this paper series, four biodiversity impact indicators are presented and discussed, which use the inventory data on habitat composition and sizes from the GIS-based inventory modeling in Part 1 (Geyer et al. 2010). The concepts used to develop characterization models are hemeroby, species
\end{abstract}

Responsible editor: Llorenc Milà i Canals

Preamble The present paper is the second in a series of two that demonstrate the potential of coupling geographic information system (GIS) technology with LCA for assessing biodiversity impacts of land use. This first paper demonstrated the use of GIS-based inventory modeling to generate elementary input flows of habitat types. This second paper presents four different characterization models that are applied to the habitat flows to calculate biodiversity impact indicators.

R. Geyer $(\bowtie) \cdot$ D. M. Stoms $\cdot$ F. W. Davis

Donald Bren School of Environmental Science and Management, University of California,

Santa Barbara, CA 93110-5131, USA

e-mail: geyer@bren.ucsb.edu

J. P. Lindner $\cdot$ B. Wittstock

Abteilung Ganzheitliche Bilanzierung, Lehrstuhl für Bauphysik,

Universität Stuttgart,

70771 Leinfelden-Echterdingen, Germany richness, species abundance, and species evenness. The biodiversity assessments based on species richness, abundance, and evenness use a species-habitat suitability matrix which relates 443 terrestrial vertebrate species native to California to the 29 habitat types that occur in the study area. Results and discussion The structural similarities and differences of all four characterization models are discussed in some detail. Characterization factors and indicator results are calculated for each of the four characterization models and the 11 different land use scenarios from Part 1 of this paper series. For the sugar beet production scenarios, the indicator results are in fairly good agreement. For the corn production scenarios, however, they come to fundamentally different results. The overall approach of using GIS-based inventory data on land use together with information on species-habitat relationships is not only feasible but also grounded in ecological science and well connected with existing life cycle impact assessment efforts.

Conclusions Excluding biodiversity impacts from land use significantly limits the scope of LCA. Accounting for land use in inventory modeling is dramatically enhanced if LCA is coupled with GIS. The resulting inventory data are a sound basis for biodiversity impact assessments, in particular if coupled with information on species-habitat relationships. However, much more case studies and structural analysis of indicators is required, together with an evaluation framework that enables comparisons and ranking of indicators.

Keywords Abundance - Biodiversity impacts - Bioethanol . Evenness - Geographic information systems (GIS) · GIS-based inventory modeling · Habitats · Hemeroby . Land use $\cdot$ Spatially explicit inventory modeling . Species richness 


\section{Introduction and background}

The purpose of life cycle assessment is to synthesize a comprehensive environmental profile of products (Rebitzer et al. 2004). For many products, the area of land required to produce the raw materials, to manufacture a functional unit of the product, and to dispose of it at the end of life is negligible and is appropriately ignored in life cycle assessment (LCA). Some production processes, however, transform and occupy substantial areas of land and thereby generate significant environmental impact. Agricultural production, including for renewable fuels, is a particularly noteworthy example, especially if it transforms high biodiversity lands such as tropical forest into lower diversity cropland (Searchinger et al. 2008). Concern that ignoring land use will yield incomplete environmental profiles has spawned a growing literature on ideas for measuring land use impacts within the LCA methodology (Baitz 1998; Lindeijer 2000; Schenck 2001; Brentrup et al. 2002; Milà i Canals et al. 2006; Koellner and Scholz 2007; Michelsen 2008). A UNEP/SETAC committee has recently proposed a conceptual framework for land use in LCA (Milà i Canals et al. 2007). Biodiversity is explicitly included as one aspect of land quality in this framework. How exactly to incorporate the framework into standard LCA practice is still a very active area of research, however.

There are several serious obstacles to achieving this goal. First, land use is an inherently spatial activity. The geographic variation in the productivity of soils means that the land area required to produce a liter of bioethanol depends on where the feedstock is grown. In addition, the impact on biodiversity of transforming land depends not only on the new use but also on the habitat type and its complement of species that would be lost through that transformation. Therefore, the impact is a function of place, not just of units of product. LCA, however, is conventionally aspatial, mostly relying on average values. Overcoming this obstacle will require more creativity than merely adding another impact category linked to the reference flow of the product or a simple tally of land area transformed and occupied.

This relationship of impact and place implies a second obstacle to land use impact assessment. The cumulative impact on biodiversity will not scale linearly with volume of production. Each marginal unit of production will transform and occupy a varying marginal land area (because of variation in productivity), and each additional unit of land may be different in its initial habitat and diversity than another unit or the "average." LCA methodology is typically linear, where elementary flows and characterization models scale linearly with activity levels and economic output.
Overcoming these substantial technical obstacles still leaves a fundamental issue of how to measure as complex a concept as biodiversity. Simply put, biodiversity is the diversity of life as a whole. The Convention on Biological Diversity defined it as "diversity within species, between species and of ecosystems" (UNEP 1992). Diversity between species is the most common way that biodiversity is interpreted in practice, such as in biological conservation planning (Margules and Pressey 2000). But which species? Any location is likely to contain thousands of species. Only the distributions of vertebrates (e.g., birds, mammals) are reasonably well known for large regions. Plant distributions are also known for many parts of the world, but typically at a coarse spatial resolution, such as a district or county or in Europe by arbitrary $50 \times 50-\mathrm{km}$ squares (Jalas and Suominen 1972-1994). Consequently, decisions must be made about which species will be practical to include in an impact assessment. Another practical decision regards which aspects of diversity to measure. The most basic metric is the number of species or species richness (Magurran 2004). Transforming 1 ha of land may make the site unsuitable for a given species, reducing the richness of that site or its alpha diversity (Whittaker 1972). What is of greater concern for conservation is maintaining the total richness of an ecoregion, or gamma diversity, which is a product of the alpha diversity of its different communities and the dissimilarity (beta diversity) between them (Whittaker 1972). To diminish gamma diversity would require the transformation of all suitable habitats for a species in an ecoregion to eliminate it from the regional species pool. Therefore, gamma diversity or richness may not be a very sensitive impact indicator. Ecologists often incorporate measures of species abundance (absolute size of their populations) or evenness (relative size of populations) along with richness for more nuanced measures of biodiversity. As a result, many different measures of biodiversity have been proposed (Magurran 2004). Koellner and Scholz (2008) offered an LCA biodiversity impact indicator based on species richness. Scholes and Biggs (2005) proposed a "biodiversity intactness indicator" that estimates the average relative abundance of all plant and vertebrate species compared to a reference condition. Burke et al. (2008) developed a form of abundancebased indicator called the "biotope method" that accounted for the relative abundance (or rarity) of narrowly distributed plants.

Geyer et al. (2010) in Part 1 presented a life cycle inventory method that used a geographic information system to calculate elementary flows of habitat types. The objective of this article was to demonstrate how a suite of characterization models can be derived analytically from two basic pieces of information: the elementary flow data and knowledge of habitat preferences of wildlife species encapsulated in a habitat suitability matrix. Four biodiversity 
impact indicators, and their associated vectors of characterization factors for habitat types, are presented. The indicators range from a simple method based on overall degradation to habitat types, to a richness-based index, to richness plus either abundance or evenness. Potential biodiversity impacts were then assessed for three bioethanol feedstocks at different production levels in the southern part of California's San Joaquin Valley, USA (Fig. 1 in Geyer et al. 2010). This region is renowned both for its agriculture (Umbach 2002) and imperiled biodiversity (USFWS 1998). We do not conclude that any of these indicators should become the standard for life cycle impact assessment. Rather, we seek to demonstrate that a wealth of information on biodiversity can be mined from relatively basic spatial and ecological data with LCA-compatible methodology. We also explore whether this LCA-compatible methodology can accommodate nonlinear biodiversity impacts in response to production level.

\section{Materials and methods}

\subsection{The scope of the impact assessment}

The first part of this paper series explained how GIS-based inventory modeling was employed to generate ten plausible fuel crop production scenarios in the four southernmost counties of California's San Joaquin Valley (Geyer et al. 2010). The scenarios included three potential bioethanol feedstocks - corn grain, corn grain and stover, and sugar beets-at various production levels. The production levels were set in order to meet increasing percentages of projected demand for ethanol in California in 2010. Each scenario consists of a detailed land use map of the entire study region, with the required amount of corn and sugar beet fields displacing current land use. A map of current land use is added as a baseline scenario. To be able to assess biodiversity impacts of the fuel crop production scenarios, the inventory model calculated habitat composition vectors $\vec{a}$ from the land use maps by identifying each land use type as a habitat type from a list of 59 mutually exclusive and collectively exhaustive standard habitat types for California (Mayer and Laudenslayer 1988). Twentynine of the 59 different habitat types are present in the study area. Corn fields, for example, belong to the irrigated grain crops (IGR) habitat type, while sugar beet fields belong to irrigated row and field crops (IRF). The areas of all land use types belonging to the same habitat type are summed up. The baseline scenario and each fuel crop production scenario is thus characterized by a vector of elementary input flows $a_{j}, j \in$ [1-29], which contains the areas (in hectares) of 29 habitat types that together make up the total study area, $A=\sum_{j} a_{j}=2,538,482$ ha.
The second part of this paper series explores ways in which these elementary flows can be used to assess the impacts that these fuel crop production scenarios may have on biodiversity. The remainder of this paper is thus dedicated to deriving and discussing characterization models and factors that translate the habitat composition vectors $\vec{a}$ into four different biodiversity indicators. They are derived from the following four concepts:

- Hemeroby, or naturalness, as proposed by Brentrup et al. (2002)

- Species richness, as proposed by Koellner and Scholz (2008)

- Species richness and abundance, developed by the authors

- Species richness and evenness, based on the Simpson index (Simpson 1949)

Hemeroby is a property of the land use or habitat type itself, which means that an indicator based on hemeroby does not require any information about the species the habitat supports. The other three indicators, on the other hand, need to relate the land or habitat type to the species that are found in it, which is the major challenge of biodiversity impact assessment models. To achieve this, three of the four indicators introduced in this paper rely heavily on a species-habitat suitability matrix, HS $\in R^{443} \times R^{29}$, which characterizes the suitability of each of the 29 habitats for 443 terrestrial vertebrate species native to the study area in California. Each matrix element is either 0 or 1 , with $h s_{i j}=1$ meaning that habitat $j$ is suitable for species $i$, i.e., its requirements for food, cover, and reproduction are met, and $h s_{i j}=0$ that it is not. The specieshabitat suitability matrix HS is based on data from the California Wildlife Habitat Relationships (CWHR) system (CDFG 2005). The CWHR information system used expert opinion to rate the suitability of each of the 59 habitat types for each native vertebrate species in four ordinal classesnil, low, moderate, and high. For this study, we treated the moderate and high ratings as suitable habitats, i.e., converted them to $h s_{i j}=1$ for species $i$ in habitat $j$, and the nil and low ratings as unsuitable habitats, i.e., converted them to $h s_{i j}=0$ for species $i$ in habitat $j$. It should be noted that specific habitat patches are not necessarily inhabited by all the species; they are suitable for and therefore should be understood as potential habitats.

\subsection{Impact assessment based on the hemeroby concept}

To assess the potential impact of a given habitat composition $\vec{a}$ on biodiversity, models are required that relate land use to habitats and habitats to biodiversity. One very basic model is the hemeroby concept which, according to 
Kowarik (1999), measures "human influence on ecosystems" by determining its "deviation from naturalness as a result of specific land use types" (Brentrup et al. 2002). According to Brentrup et al. (2002), the concept has been introduced in ecology 55 years ago, and its use in LCA has been proposed by Klöpffer and Renner 1995. Brentrup et al. (2002) converted the original cardinal scale of increasing human influence into 11 evenly spaced characterization values that increase from 0 to 1 in 0.1 increments. The hemeroby concept has been specifically proposed as an alternative to other methods that assess land use impacts on species diversity, such as the one proposed by Koellner (2003). Hemeroby-based impact assessment does not require information on species diversity, such as the species-habitat suitability matrix HS used in the other three characterization models discussed in this paper. Instead, it is based on the hypothesis that land use impacts on biodiversity increase monotonically with the level of human influence and interference. For this study, we adopted the characterization factors proposed by Brentrup et al. (2002) for European land cover/use types, called naturalness degradation potential, and assigned them to the corresponding habitat types in our study area (CF1 in Table 1).

The resulting impact assessment follows the structure of classification and characterization as described in ISO 14044 (ISO 2006). First, the elements $a_{j}$ of the habitat composition vector $\vec{a}$ are identified as the elementary flows that contribute to the biodiversity impact category. Next, the hemeroby-based biodiversity impact potential BIP1 is calculated by multiplying the elementary flows $a_{j}$ with their characterization factors $\mathrm{CF} 1_{j} \in[0,1]$ :

$\mathrm{BIP} 1=\sum_{j} \mathrm{CF} 1_{j} \times a_{j}$

It can be seen that $\mathrm{BIP} 1 \in[0, A]$, with $\mathrm{BIP} 1=A$ for maximum potential impact on biodiversity and BIP $1=0$ for minimum potential impact on biodiversity, e.g., if the entire study area were lacustrine or riverine habitat. While a hemeroby-based biodiversity impact assessment is very easy to implement, it has little theoretical or empirical underpinning. While a relationship between human influence and biodiversity is plausible, the hemeroby concept offers no environmental mechanism between the LCI results (habitat composition vector $\vec{a}$ ) and the category endpoint, which is lack of biodiversity. Such environmental mechanism can be based on theoretical models, empirical data, or combinations of the two. The CWHR system, for example, is a comprehensive data resource containing life history, geographic range, habitat relationships, and management information on 694 species of amphibians, reptiles, birds, and mammals known to occur in the state (CDFG 2005). It has been used to derive the species- habitat suitability matrix HS introduced in the previous section. The remaining three characterization models illustrate different ways in which such a matrix can be used for biodiversity impact assessment.

\subsection{Impact assessment based on species richness}

The most basic way to use the species-habitat suitability matrix HS for biodiversity impact assessment is to simply count the number of species for which a habitat type is deemed suitable, i.e., to sum up the matrix elements of each column. Each habitat type $j$ is then characterized by the number of species $S_{j}$, for which it is potential habitat:

$S_{j}=\sum_{i} h s_{i j}$.

The use of species richness data has been suggested in Koellner and Scholz (2008) who proposed a set of characterization factors called ecosystem damage potentials. Following their linear approach to convert species richness data into characterization factors $\left(\mathrm{CF}_{j}\right)$ for biodiversity impact assessment yields:

$\mathrm{CF} 2_{j}=1-\frac{S_{j}}{S_{\text {ref }}}=1-\frac{1}{S_{\text {ref }}} \sum_{i} h s_{i j}$.

The value for the reference species richness, $S_{\text {ref }}$, used in this paper is 443 , which is the number of native terrestrial vertebrates for which at least one of the occurring 29 habitat types is suitable. It can be seen from the above equation that $\mathrm{CF} 2_{j} \in[0,1]$. The value of the characterization factor decreases as the number of species increases for which the habitat type $j$ is suitable. This follows the convention that characterization factors measure the potential adverse impact that an elementary flow has for the underlying environmental concern. The resulting biodiversity impact potential BIP2 for a given land use scenario is now calculated as the scalar product of the vector of characterization factors and the habitat composition vector:

$$
\begin{aligned}
\mathrm{BIP} 2 & =\sum_{j} \mathrm{CF} 2_{j} \times a_{j}=A-\frac{1}{S_{\mathrm{ref}}} \sum_{j} \sum_{i} h s_{i j} a_{j} \text { with } \\
S_{\mathrm{ref}} & =443 \text { and } A=\sum_{j} a_{j}=2,538,482 \mathrm{ha} .
\end{aligned}
$$

It can be seen from the equation above that $\operatorname{BIP} 2 \in[0, A]$, with $\mathrm{BIP} 2=A$ if the habitat composition of the study area provides no potential habitat to any species and BIP $2=0$ if it provides potential habitat to all species everywhere. Realistic values will be somewhere in between these extremes. 
Table 1 Habitat types and their characterization factors

\begin{tabular}{|c|c|c|c|c|c|}
\hline Habitat type $(j \in[1-29])$ & $\begin{array}{l}\text { Hemeroby } \\
\left(\mathrm{CF} 1_{j}\right)\end{array}$ & $\begin{array}{l}\text { No. of suited } \\
\text { species }\left(\mathrm{S}_{j}\right)\end{array}$ & $\begin{array}{l}\text { Pure richness } \\
\left(\mathrm{CF} 2_{j}\right)\end{array}$ & $\begin{array}{l}\text { Richness and } \\
\text { abundance }\left(\mathrm{CF} 3_{j}\right)\end{array}$ & $\begin{array}{l}\text { Richness and evenness } \\
\left(\mathrm{CF} 4_{j} \times 10^{9}\right)^{\mathrm{a}}\end{array}$ \\
\hline \multicolumn{6}{|l|}{ Agricultural and urban habitats } \\
\hline DOR_-Deciduous orchard & 0.7 & 99 & 0.78 & 0.90 & 1.60 \\
\hline EOR_Evergreen orchard & 0.7 & 43 & 0.90 & 0.97 & 0.93 \\
\hline IGR_-Irrigated grain crops & 0.8 & 103 & 0.77 & 0.92 & 2.03 \\
\hline IRF-Irrigated row and field crops & 0.8 & 65 & 0.85 & 0.97 & 1.56 \\
\hline IRH_-Irrigated hayfield & 0.8 & 164 & 0.63 & 0.83 & 2.70 \\
\hline PAS-Pasture & 0.55 & 57 & 0.87 & 0.94 & 0.97 \\
\hline RIC-Rice & 0.8 & 96 & 0.78 & 0.89 & 1.47 \\
\hline URB-Urban & 0.95 & 153 & 0.65 & 0.80 & 1.96 \\
\hline VIN_-Vineyard & 0.7 & 62 & 0.86 & 0.96 & 1.30 \\
\hline \multicolumn{6}{|l|}{ Native habitats } \\
\hline AGS_-Annual grassland & 0.1 & 163 & 0.63 & 0.84 & 2.77 \\
\hline ASC_-Alkali desert scrub & 0.1 & 78 & 0.82 & 0.89 & 0.84 \\
\hline BAR-Barren & 0.8 & 85 & 0.81 & 0.87 & 0.80 \\
\hline BOP_Blue oak-foothill pine & 0.1 & 206 & 0.53 & 0.71 & 2.34 \\
\hline BOW_-Blue oak woodland & 0.1 & 205 & 0.54 & 0.71 & 2.37 \\
\hline COW_Coastal oak woodland & 0.1 & 201 & 0.55 & 0.72 & 2.33 \\
\hline CRC_-Chamise-redshank chaparral & 0.1 & 115 & 0.74 & 0.84 & 1.39 \\
\hline $\mathrm{CSC}$-Coastal scrub & 0.1 & 145 & 0.67 & 0.81 & 1.82 \\
\hline DSC—Desert scrub & 0.1 & 96 & 0.78 & 0.84 & 0.81 \\
\hline EUC_-Eucalyptus & 0.7 & 86 & 0.81 & 0.90 & 1.30 \\
\hline FEW_Freshwater emergent wetland & 0.1 & 136 & 0.69 & 0.82 & 1.65 \\
\hline JUN_-Juniper & 0.1 & 118 & 0.73 & 0.84 & 1.35 \\
\hline LAC-Lacustrine & 0 & 120 & 0.73 & 0.81 & 1.10 \\
\hline $\mathrm{MCH}-$ Mixed chaparral & 0.1 & 154 & 0.65 & 0.77 & 1.64 \\
\hline MHW-Montane hardwood & 0.1 & 178 & 0.60 & 0.73 & 1.74 \\
\hline PGS_-Perennial grassland & 0.1 & 160 & 0.64 & 0.84 & 2.64 \\
\hline RIV_-Riverine & 0 & 110 & 0.75 & 0.83 & 1.04 \\
\hline SGB-Sagebrush & 0.1 & 123 & 0.72 & 0.83 & 1.48 \\
\hline VOW_Valley oak woodland & 0.1 & 203 & 0.54 & 0.72 & 2.33 \\
\hline VRI-Valley-foothill riparian & 0.1 & 230 & 0.48 & 0.66 & 2.35 \\
\hline
\end{tabular}

Corn is part of the IGR habitat type; sugar beets are part of IRF. CF $4_{j}$ are shown here for the baseline habitat $\vec{a}^{b}$ only

${ }^{a}$ With this characterization model, every scenario has its own set of characterization factors $\mathrm{CF} 4_{j}$

Koellner and Scholz (2008) also suggest a nonlinear approach which uses the natural logarithm of the normalized species richness $\ln \left(S_{j} / S_{\text {ref }}\right)$ rather than normalized species richness itself to derive characterization factors. The idea behind this is to have a characterization model that reflects the redundant species hypothesis, which says that the marginal utility of ecosystem services is diminishing with increasing species richness. Since the presented research is concerned with biodiversity rather than ecosystem service assessment, the linear approach has been used.

While species richness is probably the most prominent aspect of biodiversity, it is only one part of a very complex concept that encapsulates the full range of life, including diversity within species, between species, and of ecosys- tems (UNEP 1992). Other important aspects of diversity between species, also called alpha diversity, are species abundance and evenness, i.e., the number of individuals for each present species and the similarity of the population sizes of similar species at the same trophic level. The characterisation models shown above and proposed by Koellner and Scholz (2008) yield pure species richness indicators which reflect neither species abundance nor evenness.

\subsection{Impact assessment based on species richness} and habitat frequency

In order to go beyond pure species richness, characterization models for biodiversity impact assessment need to capture 
additional aspects of biodiversity, such as abundance and evenness. One natural extension of the approach discussed in the previous section is to weight each species according to its rarity, i.e., lack of abundance (Lindner 2008). Using $r_{i}$ as a yet-to-be-defined rarity weight, the characterization factors can now be written as:

$\mathrm{CF}_{j}=1-\frac{1}{S_{\mathrm{ref}}} \sum_{i} r_{i} \times h s_{i j}$

Rarity rather than abundance is used in the equation above since characterization factors conventionally increase with increasing environmental impact. The rarer the species supported by habitat type $j$, the lower should thus be the habitat's characterization factor. Data on species abundance or rarity is usually generated through sampling and is even more demanding in terms of sampling techniques and effort. Sampling is not very practical in the context of LCA and even impossible if future land use changes are forecast. However, the species-habitat suitability matrix HS can be used to derive information related to relative species abundance, assuming population size increases with area. Multiplying a given habitat composition vector $\vec{a}$ with HS yields a vector that contains the total area of suitable habitat $h_{i}$ (in hectares) for each of the covered species, which are 443 native terrestrial vertebrates in the presented research:

$\vec{h}=\mathbf{H S} \times \vec{a}$ with $h_{i}=\sum_{j} h s_{i j} \times a_{j}, i \in[1-443]$.

It can be seen that for each species $i$, the above equation sums up the areas of all suitable habitat types, i.e., those $a_{j}$ for which $h s_{i j}=1$. Given a habitat composition $\vec{a}$, the resulting $h_{i}$ of a species $i$ can be used as a proxy for its abundance. To obtain unitless values between zero and one, habitat frequencies $\hat{h}_{i}$ are calculated by expressing each total area of suitable habitat $h_{i}$ as a proportion of the total study area:

$\hat{h}_{i}=\frac{h_{i}}{A}$ with $A=\sum_{j} a_{j}$ and $\hat{h}_{i} \in[0,1]$.

Since habitats support many different species, $\sum h_{i}>A$ and therefore $\sum \hat{h}_{i}>>1$. Rarity weights $r_{i}$ can now be defined in a number of ways, the simplest of which is:

$r_{i}=1-\hat{h}_{i}$ with $r_{i} \in[0,1]$.

One consequence of using the total area of potential habitat $h_{i}$ in order to account for habitat frequency is the fact that characterization factors that are based on these parameters become functions of a given habitat composition vector $\vec{a}$. This is simply a reflection of the fact that abundance or rarity of species is a property of a given region at a given point in time. It is therefore not fixed but rather a function of time and also the chosen study area. Habitat frequency therefore has to be defined for a given region at a given time. In this paper, the baseline land use scenario, i.e., the study area in its current habitat composition $\vec{a}^{b}$, has been used to derive habitat frequency data $\hat{h}_{i}$. In principle, rarity weights could be also obtained otherwise, e.g., by using threatened species lists or information on species' global habitat and population sizes.

Given the baseline habitat composition $\vec{a}^{b}, r_{i}=0$ if the entire study area $A$ is potential habitat for species $i$, and $r_{i}=$ 1 if species $i$ has no potential habitat in the study area $A$. Using the above definition for species rarity weights $r_{i}$, the resulting characterization factors are calculated as:

$$
\begin{aligned}
\mathrm{CF}_{j} & =1-\frac{1}{S_{\text {ref }}} \sum_{i}\left(1-\hat{h}_{i}\right) h s_{i j} \\
& =1-\frac{1}{S_{\text {ref }}} \sum_{i}\left(1-\frac{1}{A} \sum_{j} h s_{i j} \times a_{j}^{b}\right) h s_{i j} .
\end{aligned}
$$

In this paper, $S_{\text {ref }}=443$ and $A=2,538,482$ ha. It can be seen that the species-habitat suitability matrix HS is now used twice: once to derive potential species richness $S_{j}$ for each habitat type $a_{j}$ and again to derive species rarity weights $r_{i}$ from species' habitat frequencies $\hat{h}_{i}$. The characterization factors can also be written as:

$\mathrm{CF}_{j}=1-\frac{1}{S_{\mathrm{ref}}} \sum_{i} h s_{i j}+\frac{1}{S_{\mathrm{ref}} \times A} \sum_{i} \sum_{j}\left(h s_{i j} \times a_{j}^{b}\right) \times h s_{i j}$.

In this form, it can be seen that these characterization factors are the sum of the pure species richness factors and a correction term that accounts for habitat frequency and thus reflects species abundance. Using matrix notation to rewrite the correction term for habitat frequency, the resulting biodiversity impact potential BIP3 for a given land use scenario is:

$$
\begin{aligned}
\mathrm{BIP} 3= & \sum_{j} \mathrm{CF}_{j} \times a_{j}=A-\frac{1}{S_{\mathrm{ref}}} \sum_{j} \sum_{i} h s_{i j} \times a_{j} \\
& +\frac{1}{S_{\mathrm{ref}} \times A}\left(\mathbf{H S} \times \vec{a}^{b}\right)^{T} \mathbf{H S} \times \vec{a} .
\end{aligned}
$$

It should be noted that there are various other functions that could be used to derive rarity weights from the habitat frequency $\hat{h}_{i}$, including a simple reciprocal transformation $r_{i}=1 / \hat{h}_{i}$ as well as various forms of logistic functions, such as $r_{i}=1 /\left(a+\exp \left(\hat{h}_{i}-b\right)\right)$. At a future point, it 
would be useful to compare these different options in terms of their usefulness for biodiversity impact assessment. In this paper, the linear transformation $r_{i}=1-\hat{h}_{i}$ has been chosen since it is the most straightforward and transparent option and thus an appropriate starting point.

\subsection{Impact assessment based on species richness and habitat evenness}

The third and last way in which we employed the specieshabitat suitability matrix HS for biodiversity impact assessment is based on the Simpson index, which is a widely used biodiversity indicator that accounts for species richness and evenness (Simpson 1949). For a given sample of $N$ individuals, the Simpson index is calculated as:

$$
\mathrm{SI}=\frac{1}{N(N-1)} \sum_{l} n_{l} \times\left(n_{l}-1\right), \text { with } N=\sum_{l} n_{l}
$$

with $n_{l}$ being the number of individuals in the sample that belong to species $l$. Simpson (1949) showed that the index calculates the best estimate, given the sample size, for the probability that two individuals randomly picked from the study area belong to the same species. The indicator is sensitive to species richness and evenness since its value decreases with increasing number of species and increasing evenness of species distribution. Lower index values therefore indicate higher biodiversity. Since sampling is not very practical in the context of LCA, the species-habitat suitability matrix HS is employed to derive a biodiversity indicator that has the same mathematical structure as the Simpson index but is based on total potential habitat per species $h_{i}$ rather than number of sampled individuals $n_{l}$. This indicator is calculated as follows:

$\mathrm{BIP} 4=\frac{1}{H^{2}} \sum_{i}\left(h_{i}\right)^{2}$ with $h_{i}=\sum_{j} h s_{i j} \times a_{j}$ and $H=\sum_{i} h_{i}$.

Like the Simpson index, the indicator value decreases with increasing number of species and increasing evenness of potential habitat distribution. Noting that $\sum\left(h_{i}\right)^{2}=\vec{h}^{T} \vec{h}$ and $\vec{h}=\mathbf{H S} \times \vec{a}$, the indicator can be written in matrix notation as:

$\mathrm{BIP} 4=\frac{1}{\left(\sum_{i} h_{i}\right)^{2}}(\mathbf{H S} \times \vec{a})^{T} \mathbf{H S} \times \vec{a}$.

Comparing Eqs. 11 and 14, it can be seen that BIP4 bears strong resemblance to the habitat frequency correction term of indicator BIP3 of the previous section. This is not entirely surprising since habitat frequency and evenness are related concepts. The two differences are that the Simpson index-based indicator has a different normalization factor and uses the habitat composition of the assessed land use scenario $\vec{a}$ rather than that of the baseline scenario $\vec{a}^{b}$ to assess species abundance. The characterization factors of the Simpson index-based indicator can be derived from $\mathrm{BIP}=\sum_{j} C F_{j} \times a_{j}$ and are

$$
\mathrm{CF}_{j}=\frac{1}{\left(\sum_{i} \sum_{j} h s_{i j} \times a_{j}\right)^{2}} \sum_{i} \sum_{j}\left(h s_{i j} \times a_{j}\right) \times h s_{i j} .
$$

It can be seen that the elementary flows $a_{j}$ are required to calculate their characterization factors, which is not the case in conventional life cycle impact assessment where characterization factors tend to be independent of the elementary flows. However, ISO 14044 only states that the conversion of LCI results into indicator results uses characterization factors and does not require that characterization factors be constants. Like the characterization factors from Sections 2.2 and 2.3, CF1 and CF2, the Simpson indexbased characterization factors CF4 do not require a baseline land use scenario. Unlike the characterization factors CF1 and $\mathrm{CF} 2$, but like the characterization factor $\mathrm{CF} 3$ from Section 2.4, the Simpson index-based characterization factors CF4 are a function of habitat composition vectors. A comprehensive theoretical analysis of the structural similarities and differences between all four discussed indicators was outside the scope of the presented research and thus left to future research. Instead, the four characterization models were applied to the inventory modeling results from the fuel crop production scenarios developed and discussed in Geyer et al. (2010). The remainder of this paper discusses the results of these biodiversity impact assessments.

\section{Results}

The characterization factors of all four characterization models are shown in Table 1. It can be seen that the hemeroby-based factors CF1 offer the least amount of differentiation between the different habitat types. Of the nine agricultural or urban habitats, seven have a value of either 0.7 or 0.8 , while 18 of the 20 native habitats have a value of 0 or 0.1 . Note that the CF1 for corn and sugar beets are both 0.8 . The only difference in impacts of the two crops for a given volume of ethanol will therefore be due to the difference in their yields and the habitats they replace. CF2 simply reflects the number of species for which each habitat is deemed unsuitable. As would be 
expected, the average value for the agricultural or urban habitats $(0.79)$ is higher than the average value for the native habitats $(0.67)$. Comparing $\mathrm{CF} 1$ and $\mathrm{CF} 2$ shows that species richness is not always well reflected through the hemeroby concept. Urban habitats and irrigated hayfields are just as species-rich as mixed chaparral and annual grassland even though their hemeroby values are dramatically different. Weighting each species based on its rarity increases the characterization factors for every habitat since $\mathrm{CF} 3_{j}>\mathrm{CF} 2_{j} \Leftrightarrow \sum r_{i} h s_{i j}<\sum h s_{i j}$ and $\operatorname{avg}\left(r_{i}\right)=0.74$. The rarity weights have a more dramatic impact on habitats with large $S_{j}=\sum h s_{i j}$, which narrows the range of the $\mathrm{CF}_{j}$ to 0.32 from 0.42 for the CF2. Interestingly, value range and standard deviation for the group of agricultural or urban habitats decrease, as do value range and standard deviation for the group of native habitats. This means that accounting for species rarity makes the agricultural or urban habitats more similar to each other, which is also true for the native habitats. The Simpson index-based characterization factors CF4 cannot be easily compared with the other three factors. Whereas species richness and abundance are calculated for each individual species in isolation, evenness relates all 443 species to each other. As a result, characterization factors CF4 are different for each land use scenario, which makes their interpretation difficult. It is more meaningful to discuss BIP4 directly rather than CF4.

Table 2 contains the indicator results for all 11 land use scenarios and four characterization models. The first three indicators, BIP1, BIP2 and BIP3, are essentially weighted sums of the habitat areas $a_{j}$ describing a land use scenario.

Table 2 Biodiversity impact potentials for each scenario and characterization model

\begin{tabular}{lllll}
\hline Scenario & BIP1 & BIP2 & BIP3 & BIP4 \\
\hline Baseline & $1,422,653$ & $1,883,105$ & $2,265,559$ & 0.005102 \\
CR10 & $1,429,939$ & $1,880,993$ & $2,265,702$ & 0.005134 \\
CR25 & $1,441,063$ & $1,876,994$ & $2,265,355$ & 0.005193 \\
CS10 & $1,428,327$ & $1,881,487$ & $2,265,698$ & 0.005127 \\
CS25 & $1,436,638$ & $1,878,588$ & $2,265,510$ & 0.005168 \\
CS50 & $1,462,724$ & $1,876,109$ & $2,266,862$ & 0.005288 \\
SB10 & $1,425,056$ & $1,884,985$ & $2,267,159$ & 0.005125 \\
SB25 & $1,428,488$ & $1,887,760$ & $2,269,494$ & 0.005159 \\
SB50 & $1,434,963$ & $1,891,901$ & $2,273,072$ & 0.005218 \\
SB75 & $1,508,484$ & $1,917,307$ & $2,289,524$ & 0.005431 \\
SB100 & $1,707,205$ & $1,984,195$ & $2,333,725$ & 0.006327 \\
\hline
\end{tabular}

The goal has been defined as 1.38 billion kilograms of ethanol. The numbers in the scenario names indicate the percentage of goal achievement (for example, CS25 means $25 \%$ of ethanol production goal achieved with corn including stover conversion)

$C R$ corn grains only, $C S$ corn grains and stover, $S B$ sugar beets
Since the weights (characterization factors) are all between 0 and 1 , the resulting indicator values are all between 0 and $A$, the total study area. Smaller indicator values indicate smaller adverse biodiversity impacts. Comparing the absolute indicator results across the first three characterization models, however, is not very meaningful. To facilitate comparisons across all four indicators, all indicator results have been normalized in the following way:

$\mathrm{BIP}(X) \mapsto \overline{\mathrm{BIP}}=\frac{\mathrm{BIP}(X)-\mathrm{BIP}(\text { baseline })}{\operatorname{BIP}(S B 100)-B I P(\text { baseline })}$.

This means that $\overline{B I P}$ (baseline $)=0$ and $\overline{B I P}(S B 100)=1$. The results can be seen in Table 3 and have also been visualized separately for each ethanol feedstock in Figs. 1, 2, and 3 .

It is important to discuss the results in the context of the underlying inventory modeling, which is discussed in detail in Part 1 of this paper series (Geyer et al. 2010). While the entire study region with its $2,538,482$ ha and 29 habitat types has been modeled for each fuel crop production scenario, the vast majority of habitat type area changes happens within just six habitat types, which are deciduous orchard (DOR), IGR, IRF, irrigated hayfield (IRH), vineyard (VIN), and annual grassland (AGS). Table 4 shows the percentage to which the fuel crop habitat increases come from the habitat types listed above. $\Delta a_{\mathrm{DOR}} / \Delta a_{\mathrm{IGR}}(\mathrm{CR} 10)=-28 \%$, for example, means that $28 \%$ of the land converted to corn fields in the CR 10 scenario was of the habitat type DOR. It can be seen that corn production scenarios convert overwhelmingly DOR, IRF, IRH, and VIN into IGR. The first three sugar beet

Table 3 Percentage change of biodiversity impact potentials relative to baseline scenario for each scenario and characterization model

\begin{tabular}{lcccc}
\hline Scenario & BIP1 (\%) & BIP2 (\%) & BIP3 (\%) & BIP4 (\%) \\
\hline Baseline & 0.0 & 0.0 & 0.0 & 0.0 \\
CR10 & 2.6 & -2.1 & 0.2 & 2.6 \\
CR25 & 6.5 & -6.0 & -0.3 & 7.4 \\
CS10 & 2.0 & -1.6 & 0.2 & 2.0 \\
CS25 & 4.9 & -4.5 & -0.1 & 5.4 \\
CS50 & 14.1 & -6.9 & 1.9 & 15.2 \\
SB10 & 0.8 & 1.9 & 2.3 & 1.8 \\
SB25 & 2.1 & 4.6 & 5.8 & 4.6 \\
SB50 & 4.3 & 8.7 & 11.0 & 9.5 \\
SB75 & 30.2 & 33.8 & 35.2 & 26.8 \\
SB100 & 100.0 & 100.0 & 100.0 & 100.0 \\
\hline
\end{tabular}

Percentage changes have been normalized to scenario SB100, which has the highest biodiversity impact potential for each characterization model 


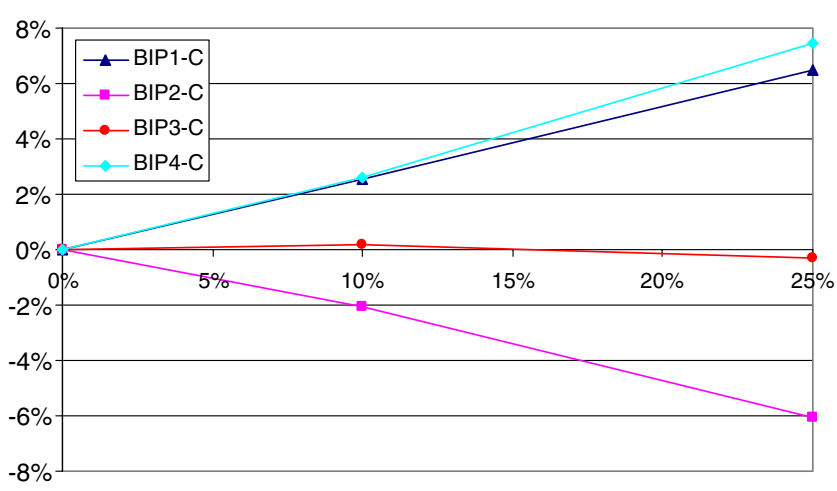

Fig. 1 Percentage change of biodiversity impact potentials relative to baseline scenario for corn grain only production scenarios $(C R)$

production scenarios, SB10, SB25, and SB50, convert overwhelmingly DOR, IGR, IRH, and VIN into IRF. In the remaining two sugar beet production scenarios, SB75 and SB100, large areas of AGS are turned into sugar beet fields as well. The relationship between the characterization factors of these six habitat types is thus the key to understanding the indicator results.

Figures 1 and 2 show the biodiversity indicator results for the corn production scenarios (with and without stover). While the hemeroby- and Simpson index-based indicators BIP1 and BIP4 are in good agreement, the other two indicators come to very different conclusions. According to BIP1 and BIP4, increasing corn production increases potential impact on biodiversity. In contrast, BIP2 indicates a reduction in biodiversity impacts as corn production increases, while biodiversity impacts according to BIP3 are roughly constant. In other words, the indicators fundamentally disagree on the biodiversity impacts of the corn production scenarios. The discrepancy in the indicator results follows from the relative differences in the characterization factors. $\mathrm{CF} 1_{I G R} \geq \mathrm{CF} 1_{k} k \in[\mathrm{DOR}, \mathrm{IRF}, \mathrm{IRH}$, VIN], so converting a mix of DOR, IRF, IRH, and VIN into IGR will increase BIP1. In contrast, $\mathrm{CF} 2_{I G R}<\mathrm{CF} 1_{k} k$ $\in[$ DOR, IRF, VIN], which explains why BIP2 decreases

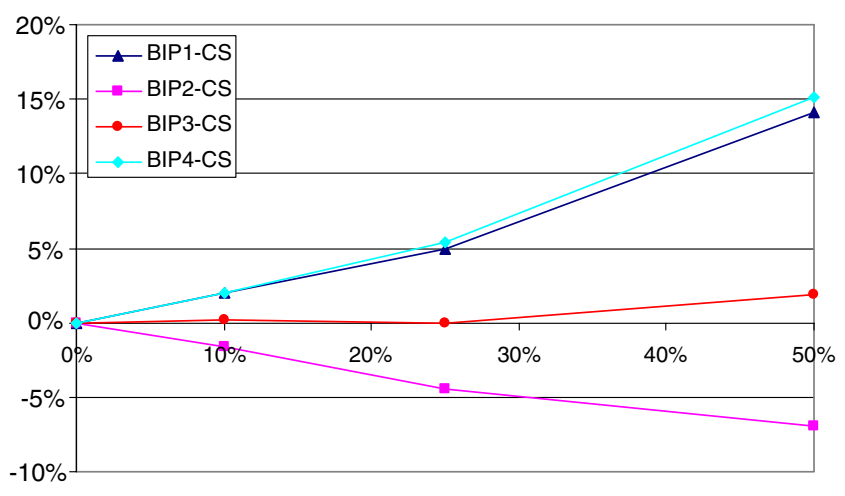

Fig. 2 Percentage change of biodiversity impact potentials relative to baseline scenario for corn grain and stover production scenarios $(C S)$

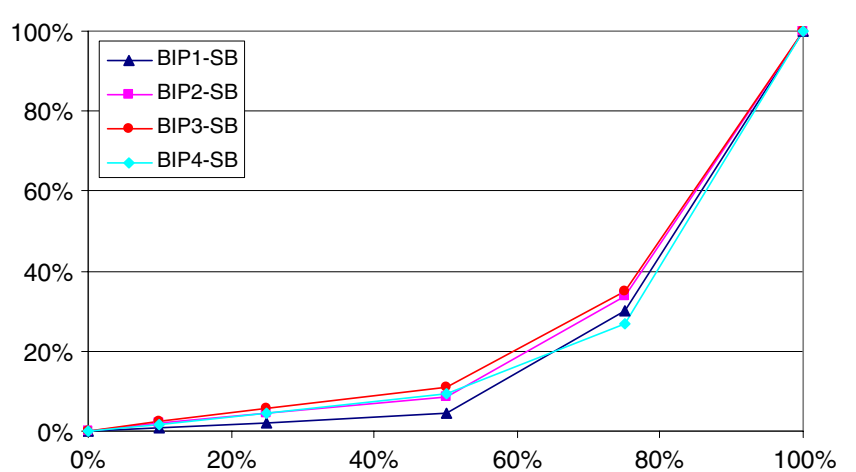

Fig. 3 Percentage change of biodiversity impact potentials relative to baseline scenario for sugar beet production scenarios $(S B)$

with increasing corn production. $\mathrm{CF} 3_{\mathrm{IGR}}$ is larger than the values for DOR and IRH, but smaller than those for IRF and VIN, which explains why BIP3 is hardly affected by the corn production scenarios. $\mathrm{CF}_{I G R}\left(\vec{a}^{b}\right)$ is considerably larger than the values for DOR, IRF, and VIN, which together make up $70-80 \%$ of the converted habitats. However, the Simpson index-based characterization factors change with each crop production scenario, which complicates this kind of analysis.

Figure 3 shows the biodiversity indicator results for the sugar beet production scenarios. Here, the results for all four indicators are in fairly good agreement. All four indicators conclude that increasing sugar beet production in the study area increases the potential impact on biodiversity. For all four indicators, the increase in potential biodiversity impact is modest for the first three production targets, SB10, SB25, and SB50, but rather dramatic for SB75 and SB100. The most significant reason for this nonlinearity is that SB75 and SB100 convert large areas of AGS into IRF (see Table 4). However, they also increasingly use other native habitat types such as ASC, BOW, and MCH (see Geyer et al. 2010 for habitat composition details) with characterization factors much lower than those for IRF.

Tables 2 and 3 also allow comparisons across fuel crop types for given ethanol output and indicator choice. It can be seen that the four indicators come to conflicting results, which is due to their different assessments of the corn production scenarios. BIP1 and BIP4 conclude that for a given ethanol target, sugar beet generates less potential biodiversity impact than corn, with or without stover. BIP2 and BIP3 come to the opposite conclusion.

\section{Discussion}

This paper discusses and applies four different characterization models for an important environmental mechanism, which is the potential impact of land use on biodiversity. It is important to recognize that other environmental 
Table 4 Habitat area changes in percent of fuel crop habitat increase, i.e., $\Delta a_{j} / \Delta a_{\mathrm{IGR}}$ for corn production scenarios and $\Delta a_{j} / \Delta a_{\mathrm{IRF}}$ for sugar beet production scenarios

\begin{tabular}{lccccccc}
\hline Scenario & DOR (\%) & IGR (\%) & IRF (\%) & IRH (\%) & VIN (\%) & AGS (\%) & Other (\%) \\
\hline CR10 & -28 & & -25 & -16 & -24 & -3 & -4 \\
CR25 & -24 & & -24 & -16 & -30 & -3 & -3 \\
CS10 & -29 & & -25 & -16 & -23 & -3 & -4 \\
CS25 & -24 & & -25 & -17 & -28 & -2 & -4 \\
CS50 & -22 & & -25 & -16 & -24 & -6 & -7 \\
SB10 & -26 & -20 & & -11 & -37 & -1 & -5 \\
SB25 & -23 & -19 & & -12 & -41 & -1 & -4 \\
SB50 & -21 & -21 & & -10 & -43 & -1 & -4 \\
SB75 & -16 & -15 & & -6 & -27 & -30 & -6 \\
SB100 & -9 & -10 & & -4 & -14 & -49 & -14 \\
\hline
\end{tabular}

interventions, such as toxic releases, can also impact biodiversity, while land use can impact safeguard objectives other than biodiversity, such as water purification and nutrient cycling. Such mechanisms are outside the scope of the presented research. How to generate inventory data that describe land use of product systems and contain enough pertinent information to characterize its potential impact on biodiversity was presented in the first part of this paper series. This second part focuses entirely on the characterization of the inventory results, i.e., the habitat composition vectors $\vec{a}$.

Apart from the very simple hemeroby-based approach, all discussed characterization models are based on the species-habitat suitability matrix HS. This is motivated in equal measure by the widespread availability of this type of information and its usefulness in characterizing biodiversity. HS is very similar to a presence-absence matrix which, according to Arita et al. (2008), is the basic analytical tool underlying many biogeographic species diversity studies and concepts. Arita et al. (2008) emphasize the many different ways in which a presence-absence matrix can be analyzed. As with the HS matrix, analysis by columns alone yields species richness per site, whereas analysis by row yields species distribution. Considering the interaction of rows and columns offers more sophisticated insights into the relationship between biogeography and biodiversity. The matrix approach presented here and in Arita et al. (2008) appears to be an excellent way to link LCA with ecology and should be studied in more detail in theory and practice. For example, the matrix elements of HS were reduced in this study to either 0 or 1 . They could also reflect the four suitability levels of the CWHR information system, e.g. $0,0.3,0.7$, and 1 for no, low, moderate, and high suitability, respectively, or be modeled as continuous values (Gottschalk et al. 2005). It is not obvious how this would change the indicator results since the matrix values would increase for some species-habitat relationships and decrease for others. Species-habitat relationships have been compiled around the world, particularly in the USA through the Gap Analysis Program (Scott et al. 1993), but are still relatively scarce in tropical regions (Gottschalk et al. 2005).

The emerging standard in the assessment of land use impacts within LCA is to describe land use in terms of area affected, duration of the land use, and change in land quality due to the land use (Milà i Canals et al. 2007). It is also customary to describe land use as a combination of transformation and occupation impacts (Milà i Canals et al. 2007). Transformation is typically defined as a more or less instantaneous change in the properties of the land (measured in area). Occupation is usually defined as the actual use of the land for some purpose (measured in areatime) where changes in the properties of the land are accidental and tolerated rather than intended. Standard land use scenarios consist of a transformation process followed by a time-limited occupation and subsequent relaxation. A lot of attention has been paid to this temporal aspect of land use (see, e.g., Guinée 2002; Koellner and Scholz 2007; Milà i Canals et al. 2007). In order to focus entirely on the unresolved problem of how to measure "land quality" in terms of biodiversity impact, the presented research is based on transformations followed by infinite occupation. At a later point, the emerging characterization models should be extended to include the temporal aspects of how land use impacts biodiversity.

A much discussed issue for characterization models of land use impacts is the need for a reference state against which the impacts are to be measured (Milà i Canals et al. 2007). It should be noted that three out of the four discussed characterization models do not require a reference state to calculate a biodiversity indicator result for a given habitat composition vector. Hemeroby and potential species richness are absolute qualities of each habitat type, while the habitat evenness calculated by indicator BIP4 is an absolute property of the given habitat composition. Only in the case of BIP3 was the calculation of potential species abundance $\vec{h}$ based on the baseline habitat composition vector, which therefore constituted a reference state for species abundance. In principle, however, the rarity weights 
$r_{i}=1-\hat{h}_{i}$ used for BIP3 could be based on the studied habitat composition $\vec{a}$ rather than the baseline $\vec{a}^{b}$. Typically, the biodiversity impacts of habitat composition vectors will be compared against each other. The object of study is then a land use change, with the initial land use scenario as a de facto reference state. Future research should further look into the relationship between reference states and attributional versus consequential perspectives.

For all three crop types, corn grains only (CR), corn grains and stover (CS), and sugar beets (SB), and all four indicators, the relationship between ethanol output and potential biodiversity impact is distinctly nonlinear. This nonlinearity therefore appears to be a robust effect independent of fuel crop and indicator choice. There are two factors that cause this nonlinearity: The first factor is the nonlinear relationship between fuel crop area and ethanol output (see Fig. 3 in Geyer et al. 2010). As ethanol output increases, less and less productive areas are converted for fuel crop production, which causes the ethanol area function to be convex. While the convexity is a property of the profit-based land conversion modeling, the nonlinearity is generic. The second factor is the fact that increasing ethanol output leads to conversion of increasing amounts of native habitats, which tend to have smaller characterization factors than agricultural habitats. This increases the potential biodiversity impact per hectare of converted land. That both nonlinearities are being accounted for is due to the use of total ethanol output as reference flow rather than some fixed arbitrary amount. It is straightforward to derive average and marginal data from total input-output relationships, but not vice versa. This suggests that inventory and impact models that are based on absolute activity or output levels are better suited to capture nonlinearities than models that use average or marginal data.

One conspicuous outcome of the San Joaquin Valley case study is that even simple indicators based on different aspects of biodiversity can come to fundamentally different results. To better understand the reasons for this, more practical applications and systematic theoretical analysis of the four indicators are required. In retrospect, the presented case study can be seen as challenging since it mostly consists of conversions from one agricultural land use/ habitat type to another. It is possible that more dramatic conversions from exclusively natural habitats to exclusively agricultural habitats would produce more consistent results. However, in the long run, it would be desirable to develop characterization models that are capable of meaningful and robust biodiversity assessments of relatively subtle land use changes. This includes the ability to distinguish not only between different agricultural land uses, such as orchards versus grain crops, but also practices, such organic versus conventional farming or different tillage practices.
Finally, the use of terrestrial vertebrates as indicator species needs to be reexamined in future research. It is currently unclear how robust characterization factors and impact indicator results are with regard to the selected species group. It is known that species richness among taxonomic groups is only weakly correlated (Wolters et al. 2006). This issue will be a major aspect of our subsequent research.

\section{Conclusions}

Comprehensive inventory data on habitat types and areas, derived from GIS-based inventory modeling of land use, are a sound basis from which to conduct biodiversity impact assessment of land use. The next step is to develop characterization factors that relate such inventory data to the category indicator, which is biodiversity. While characterization factors for different land use/habitat types can be derived directly from concepts such as hemeroby, more detailed environmental mechanisms, such as theoretical or empirical species-habitat relationships, provide more detailed and scientific characterization models. Species-habitat suitability matrices, for example, are powerful tools that allow the derivation of data on potential species richness, abundance, and evenness. The use of species-habitat suitability matrices for biodiversity impact assessment of land use is very promising. The presented case study of fuel crop production scenarios in California's San Joaquin Valley, however, shows that at least in the case of habitat changes limited mostly to agricultural types, different characterization models generate contradicting results, even if they are based on the same matrix.

As can be seen from the equations, the biodiversity indicators BIP2, BIP3, and BIP4 use only the specieshabitat suitability matrix HS and the habitat composition vectors from the inventory analysis. The GIS-based inventory modeling generates comprehensive land use and habitat maps of the entire study area and therefore contains considerably more information than the habitat composition vectors convey. This additional information could, in principle, be used for more advanced biodiversity assessments. When aggregating all habitat patches of the same habitat type, for example, patches could be eliminated if they are below a defined minimum size and therefore not viable for given species. In addition to total area, the connectivity or fragmentation of habitats could be assessed. Another possibility would be to model and account for edge effects. The potential for using spatial data generated by GIS-based inventory modeling for biodiversity impact assessment, as well as other impact categories, is enormous and offers a wealth of research opportunities.

There are currently no methods available to assess how suitable, meaningful, and scientific a given biodiversity 
indicator is, which is why we refrained from making recommendations. There is thus an urgent need for an evaluation framework that allows for comparative assessments of the strengths and weaknesses of these and other potential biodiversity indicators of land use. Such a framework should identify and prioritize the biodiversity aspects that indicators should reflect and also specify how proposed indicators can be measured against these criteria and compared with each other. Otherwise, we will face further proliferation of competing characterization models. Comparative assessments should be equally based on practical applications of the studied characterization models and their conceptual and systematic theoretical analysis.

Acknowledgments The University of California Energy Institute provided funding for this study. PE International contributed data for the life cycle inventory models.

Open Access This article is distributed under the terms of the Creative Commons Attribution Noncommercial License which permits any noncommercial use, distribution, and reproduction in any medium, provided the original author(s) and source are credited.

\section{References}

Arita HT, Christen JA, Rodríguez P, Sobéron J (2008) Species diversity and distribution in presence-absence matrices: mathematical relationships and biological implications. Am Nat 172 (4):519-532

Baitz M (1998) Die Bedeutung der funktionsbasierten Charakterisierung von Flächen-Inanspruchnahme in industriellen Prozesskettenanalysen. Shaker, Aachen

Brentrup F, Küsters J, Lammel J, Kuhlmann H (2002) Life cycle impact assessment of land use based on the hemeroby concept. Int $\mathrm{J}$ LCA 7(6):339-348

Burke A, Kyläkorpi L, Rydgren B, Schneeweiss R (2008) Testing a Scandinavian biodiversity assessment tool in an African desert environment. Environ Manage 42(4):698-706

CDFG (2005) California wildlife habitat relationships database 8.1. California Department of Fish and Game (CDFG), Sacramento, USA. http://www.dfg.ca.gov/biogeodata/cwhr/

Geyer R, Stoms DM, Lindner JP, Davis FW, Wittstock B (2010) Coupling GIS and LCA for biodiversity assessments of land use. Part 1: inventory modeling. Int J LCA 15:454-467. doi:10.1007/ s11367-010-0170-9

Gottschalk TK, Huettmann F, Ehlers M (2005) Thirty years of analysing and modelling avian habitat relationships using satellite imagery data: a review. Int J Remote Sens 26 (12):2631-2656

Guinée JB (ed) (2002) Handbook on life cycle assessment, operational guide to the ISO standards. Kluwer, Dordrecht

ISO (2006) ISO 14044: Environmental management-life cycle assessment - requirements and guidelines. ISO/FDIS 14044:2006 (E), ISO, Genève, Switzerland

Jalas J, Suominen J (eds) (1972-1994) Atlas florae europaeae. Distribution of vascular plants in Europe, vols 1-10. The Committee for Mapping the Flora of Europe and Societas Biologica Fennica Vanamo, Helsinki

Koellner T (2003) Land use in product life cycles and ecosystem quality. Peter Lang, Bern
Koellner T, Scholz RW (2007) Assessment of land use impacts on the natural environment. Part 1: an analytical framework for pure land occupation and land use change. Int J LCA 12(1):16-23

Koellner T, Scholz RW (2008) Assessment of land use impacts on the natural environment. Part 2: generic characterization factors for local species diversity in Central Europe. Int J LCA 13(1):32-48

Klöpffer W, Renner I (1995) Methodik der Wirkungsbilanz im Rahmen von Produkt-Ökobilanzen unter Berücksichtigung nicht oder nur schwer quantifizierbarer Umwelt-Kategorien. in: UBA (1995): Methodik der produktbezogenen ÖkobilanzenWirkungsbilanz und Bewertung. Texte 23/95. Umweltbundesamt (UBA), Berlin

Kowarik I (1999) Natürlichkeit, Naturnähe und Hemerobie als Bewertungskriterien. In: Konold W, Böcker R, Hampicke U (eds) Handbuch Naturschutz und Landschaftspflege. ecomed, Landsberg, Germany

Lindeijer E (2000) Biodiversity and life support impacts of land use in LCA. J Clean Prod 8(4):313-319

Lindner JP (2008) Development of an indicator for biodiversity consideration in life cycle assessment. Master's thesis, Universität Stuttgart, Stuttgart, Germany

Magurran AE (2004) Measuring biological diversity. Blackwell, Oxford

Mayer KE, Laudenslayer WF (eds) (1988) A guide to wildlife habitats of California. State of California Resources Agency, Sacramento

Margules CR, Pressey RL (2000) Systematic conservation planning. Nature 405:243-253 (11 May 2000)

Michelsen O (2008) Assessment of land use impacts on biodiversity proposal of a new methodology exemplified with forestry operations in Norway. Int J LCA 13(1):22-31

Milà i Canals L, Clift R, Basson L, Hansen Y, Brandão M (2006) Expert workshop on land use impacts in life cycle assessment. Int J LCA 11(5):363-368

Milà i Canals L, Bauer C, Depestele J, Dubreuil A, Freiermuth Knuchel R, Gaillard G, Michelsen O, Müller-Wenk R, Rydgren B (2007) Key elements in a framework for land use impact assessment within LCA. Int J LCA 12(1):5-15

Rebitzer G, Ekvall T, Frischknecht R, Hunkeler D, Norris G, Rydberg T, Schmidt WP, Suh S, Weidema BP, Pennington DW (2004) Life cycle assessment. Part 1: framework, goal and scope definition, inventory analysis, and applications. Env Int 30:701-720

Schenck RC (2001) Land use and biodiversity indicators for life cycle impact assessment. Int J LCA 6(2):114-117

Scholes RJ, Biggs R (2005) A biodiversity intactness index. Nature 434:45-49

Scott JM, Davis F, Csuti B, Noss R, Butterfield B, Groves C, Anderson H, Caicco S, D'Erchia F, Edwards TCJ, Ulliman J, Wright RG (1993) Gap analysis: a geographic approach to protection of biological diversity. Wildlife Monographs 123:1-41

Searchinger T, Heimlich R, Houghton RA, Dong F, Elobeid A, Fabiosa J, Tokgoz S, Hayes D, Yu T-H (2008) Use of U.S. croplands for biofuels increases greenhouse gases through emissions from landuse change. Science 319(5867): $1238-1240$

Simpson EH (1949) Measurement of diversity. Nature 163:688

Umbach KW (2002) San Joaquin Valley. Selected statistics on population, economy, and environment. Prepared at the request of the Senate Select Committee on Central Valley Economic Development. California Research Bureau, Sacramento, California

USFWS (1998) Recovery plan for upland species of the San Joaquin Valley, California. US Fish and Wildlife Service (USFWS), Region 1, Portland, Oregon

UNEP (1992) Convention on biological diversity. Treaty Series No. 30619. United Nations Environmental Program (UNEP), New York

Whittaker RH (1972) Evolution and measurement of species diversity. Taxon 21(2/3):213-251

Wolters V, Bengtsson J, Zaitsev AS (2006) Relationship among the species richness of different taxa. Ecology 87(8):1886-1895 